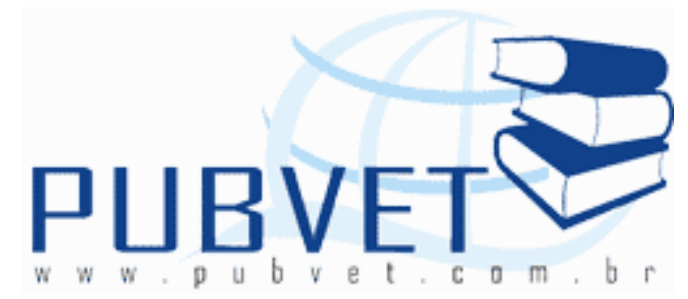

PUBVET, Publicações em Medicina Veterinária e Zootecnia.

\title{
Uso da glicerina bruta na alimentação animal
}

Jéssica Santos Tigre ${ }^{1}$ e José Augusto Gomes Azevedo ${ }^{2}$

${ }^{1}$ Médica Veterinária, Mestre em Ciência Animal com ênfase em Nutrição de Ruminantes - UESC.

${ }^{2}$ Docente do Departamento de Ciências Agrárias e Ambientais DCAA/UESC

\section{Resumo}

A glicerina bruta ao ser absorvida pelo rúmen ou intestino delgado, torna-se um precursor de glicose para as vias gliconeogênicas e produção de ácidos graxos voláteis. Esta revisão tem por objetivo descrever as vantagens e desvantagens do uso da glicerina bruta na alimentação animal, visando diminuir o impacto ambiental, causado pelo acúmulo de resíduos na natureza.

Palavras-chave: biodiesel, frangos, glicerol, ruminantes, subprodutos

\section{Use of crude glycerin in animal feed}

\section{Summary}

The crude glycerol to be absorbed into the rumen or intestine becomes a precursor of glucose to the gluconeogenic pathwaysand production of volatile fatty acids. This review aims to describe the advantages and disadvantages of the use of crude glycerin in animal feed in order to reduce the environmental impact caused by the accumulation waste in nature.

Keywords: biodiesel, chickens, glycerol, ruminant by-products 
TIGRE, J.S. e AZEVEDO, J.A.G. Uso da glicerina bruta na alimentação animal. PUBVET, Londrina, V. 6, N. 26, Ed. 213, Art. 1421, 2012.

\section{INTRODUÇÃO}

As pastagens nativas são à base da alimentação da ovinocultura na região nordeste. Porém, o desempenho dos animais criados exclusivamente a pasto geralmente é menor que o determinado geneticamente e, o desejado para satisfazer os objetivos da produção. Isto porque, a eficiência máxima de utilização da dieta resulta do fornecimento de dietas balanceadas nutricionalmente. A consequência de sistemas de produção baseados em forragens é que o desempenho animal é limitado a aquele suportado pelo primeiro nutriente limitante.

Nos sistemas de produção eficientes a suplementação é adotada como uma prática tecnológica de apoio à pastagem, com vistas a uma produção compatível com o mérito genético dos animais e o propósito da criação. O uso de alimentos alternativos não convencionais vem despertando o interesse dos produtores e incentivado pela indústria e órgãos governamentais devido a questões ambientais e considerações econômicas. Entre os subprodutos de interesse para uso na suplementação, a glicerina, proveniente da indústria dos biocombustíveis, surge como opção. Segundo a Agência Nacional do Petróleo, Gás Natural e Biocombustíveis (ANP) o biodiesel é um combustível produzido a partir de óleos vegetais ou de gorduras animais. Dezenas de espécies vegetais presentes no Brasil podem ser usadas na produção do biodiesel, entre elas soja, dendê, girassol, babaçu, amendoim, mamona e pinhão-manso, para se tornar compatível com os motores a diesel, o óleo vegetal precisa passar por um processo químico chamado transesterificação, realizado nas instalações produtoras de biodiesel autorizadas pela ANP, desse processo resulta a glicerina utilizada na alimentação animal.

Os resíduos produzidos no processo de fabricação do biodiesel são uma boa alternativa para as regiões onde existe redução de alimentos ao longo do ano, não diminuindo, desta forma, a produção animal.

A exigência mundial para redução do uso de combustíveis fósseis e emissão de gases de efeito estufa, visando à sustentabilidade ambiental, favorece o crescimento do uso de fontes renováveis de energia, porém produtos 
TIGRE, J.S. e AZEVEDO, J.A.G. Uso da glicerina bruta na alimentação animal. PUBVET, Londrina, V. 6, N. 26, Ed. 213, Art. 1421, 2012.

secundários são gerados no processo de produção do biocombustível e nem todos possuem mercado definido para a sua comercialização.

O objetivo deste trabalho foi descrever as vantagens e desvantagens do uso da glicerina bruta na alimentação animal.

\section{DESENVOLVIMENTO}

\section{Biodiesel}

O biodiesel vem ganhando destaque mundialmente por ser biodegradável e não tóxico isto porque seu uso não libera gases tóxicos como enxofre e compostos aromáticos quando comparado ao petróleo. O uso do biodiesel pode ser justificado por alguns benefícios principalmente por ser uma fonte renovável de energia, redução da emissão de gases poluentes (Quintela, et al., 2009).

Segundo o programa nacional de produção e uso de biodiesel (PNPB) o Brasil apresenta potencial para a plantação das oleaginosas que são usadas na produção do biodiesel, devido à diversidade climática de ecossistemas. Porém, na produção de biodiesel gera-se produtos secundários (subprodutos) que podem ser potencialmente poluentes.

Segundo a ANP, desde $1^{\circ}$ de janeiro de 2010, o óleo diesel comercializado em todo o Brasil contém $5 \%$ de biodiesel. Esta regra foi estabelecida pela Resolução no 6/2009 do Conselho Nacional de Política Energética (CNPE), publicada no Diário Oficial da União (DOU) em 26 de outubro de 2009, que aumentou de $4 \%$ para $5 \%$ o percentual obrigatório de mistura de biodiesel ao óleo diesel. Este processo de aumento do percentual de adição de biodiesel ao diesel demonstra o sucesso do Programa Nacional de Produção e Uso do Biodiesel e da experiência acumulada pelo Brasil na produção e no uso em larga escala de biocombustíveis. Além disso, este aumento da produção e o uso do biodiesel no Brasil propiciam o desenvolvimento de uma fonte energética sustentável sob os aspectos ambiental, econômico e social. 
TIGRE, J.S. e AZEVEDO, J.A.G. Uso da glicerina bruta na alimentação animal. PUBVET, Londrina, V. 6, N. 26, Ed. 213, Art. 1421, 2012.

\section{Glicerina na produção do biodiesel}

A glicerina provém do processo de transesterificação do óleo na transformação de metil e ésteres de ácidos graxos da produção do biodiesel, ou seja, ocorre quando os triacilglicerois de origem animal reagem com o metanol, na presença de um catalisador, produzindo glicerol (subproduto) e o éster metílico de ácido graxo (biodiesel) (Donkin et al., 2009).

O glicerol é incolor, inodoro, higroscópico e um líquido doce de aparência viscosa, podendo ser apresentada com outros nomes como: glicerol, propane1, 2,3-triol, 1,2,3-propanetriol, 1,2,3-trihydroxypropano e álcool glicerol, além disso devido ao seu sabor adocicado pode ser chamado por álcool açúcar (Donkin \& Doane, 2008).

O processo de transesterificação é vantajoso porque $0,92 \mathrm{~kg}$ de glicerina crua são produzidos para cada $10 \mathrm{~L}$ de biodiesel produzido. A glicerina apresenta potencial para ser utilizada como suplemento na alimentação animal no semiárido, devido à menor disponibilidade de alimentos, escassez e irregularidade das chuvas, fazendo com que haja menor disponibilidade de alimento para os animais ao longo do ano. (Ferreira et al., 2009).

A legislação norte-americana atribui ao glicerol o status GRAS (geralmente reconhecido como seguro), quando usado como aditivo alimentar segundo as boas normas de fabricação e alimentação, inclusive na alimentação humana (FDA, 2006). No Brasil, o Ministério da Agricultura Pecuária e Abastecimento (MAPA), juntamente com a Agência Nacional de Vigilância Sanitária (ANVISA), por meio da resolução 386/1999, coloca o glicerol na lista de aditivos permitidos para a alimentação humana e animal.

$\mathrm{Na}$ indústria, quando purificada, várias são as aplicações da glicerina, entre as quais se destacam o uso em tabaco, alimentos, bebidas e cosméticos. No entanto este processo de purificação tem elevado custo, gerando a busca por alternativas para seu uso na forma bruta (Peres et al.,2005). 
TIGRE, J.S. e AZEVEDO, J.A.G. Uso da glicerina bruta na alimentação animal. PUBVET, Londrina, V. 6, N. 26, Ed. 213, Art. 1421, 2012.

\section{Metabolismo do glicerol no rúmen}

Segundo Donkin et al. (2009), através da analise in vitro a glicerina apesar de não ser um carboidrato, no rúmen é convertida em ácidos graxos voláteis (AGV), principalmente, o propionato e acético e observa-se diminuição da quantidade de produção de ácido butírico o qual observa-se que os microrganismos do rúmen se adaptam facilmente a alimentação a base de glicerina. A glicerina pode ser usada na alimentação de ruminantes como fonte de energia, além de diminuir o impacto ambiental causado por acúmulo de resíduos na natureza, os ruminantes se adaptam a nova dieta sem afetar seu rendimento e sem provocar alterações nos microrganismos presentes no rúmen. Além disso, segundo Roger et al. (2008) o uso da glicerina promoveu crescimento, adesão e atividade celulolítica de dois tipos de microrganismos o Ruminococcu flavefaciens e Fibrobacter succinogenes, indispensáveis no processo de degradação das fibras e conversão de energia no rúmen.

O glicerol também pode ser absorvido diretamente pelo epitélio ruminal, sendo convertido em glicose no fígado pela enzima glicerol quinase que converte glicerol e ATP a glicerol-3-fosfato e ADP ao nível de triose fosfato, direcionando o glicerol para a gliconeogênese (Lage et al., 2010).

O glicerol ao ser absorvido pelo do rúmen ou intestino delgado, torna-se um precursor de glicose nas vias gliconeogênicas do fígado, no rúmen, o glicerol é fermentado pelas bactérias, produzindo ácidos graxos voláteis, mas apenas o propionato contribui para a produção de glicose (Neilsen \& Ingvartsen 2004).

\section{Vantagens do uso da glicerina em ruminantes}

O processo de cetose observado em vacas leiteiras de alta produção ocorre devido ao balanço energético negativo, principalmente pelo decréscimo de absorção de propionato ruminal e carência de glicose. Porém, quando o animal é alimentado com uma dieta à base de glicerina há o fornecimento de glicose num total de 15 a $20 \%$ da demanda de glicose no período de transição (DeFrain et al., 2004). 
TIGRE, J.S. e AZEVEDO, J.A.G. Uso da glicerina bruta na alimentação animal. PUBVET, Londrina, V. 6, N. 26, Ed. 213, Art. 1421, 2012.

Osborne et al., (2009), observaram que a ingestão de uma ração contendo glicerina faz com que as vacas passem com sucesso pelo período de transição, isso é explicado devido ao rápido fornecimento de energia, já que no período final da gestação observa-se aumento da demanda de energia, além disso, foi observado redução dos níveis de amônia ruminal e uréia no sangue. Já Chung et al., 2007, avaliando a ingestão, produção de leite e concentração de glicose no sangue de vacas leiteiras da raça holandesa, no período de 21 dias após o parto, recebendo uma alimentação a base de glicerina em pó por 6 semanas, foi observado que a partir da terceira semana houve maior disponibilidade de energia auxiliando no período de transição, maior quantidade de glicose no sangue, bem como, aumento no consumo de alimentos e maior produção de leite.

De acordo com a quantidade de glicerina na dieta, Drackley (2007) percebeu que não ocorre diminuição da ingestão de alimentos, alteração de desempenho em ruminantes em crescimento ou vacas de lactação, considerando nível do uso da glicerina até $10 \%$ da matéria seca da dieta.

Segundo Mach et al. (2009), avaliando a qualidade da carne de touros da raça Holandesa em dietas a base de altas quantidades de concentrado, observaram que a osmolalidade do líquido ruminal não foi afetado nem a quantidade de produção de ácidos graxos voláteis pelo uso de $12 \%$ da glicerina. Já uma dieta com nível de $8 \%$ houve um decréscimo do $\mathrm{pH}$ e diminuição de AGV, porém essa diminuição do $\mathrm{pH}$ ruminal não teve qualquer impacto sobre o desempenho e a saúde animal.

Outro fator interessante do uso da glicerina observado pelos autores no nível de $8 \%$ de glicerina na dieta, promoveu aumento do nível sérico de insulina sendo um fator positivo devido à prevenção de diurese osmótica, além disso, a produção de insulina apresenta-se maior do que a concentração de glicose produzida, neste caso observa-se melhoria da qualidade da carcaça devido ao aumento intramuscular do teor de gordura, apresentando melhor resultado do que nos bovinos com dietas a $12 \%$ ou sem glicerina. 
TIGRE, J.S. e AZEVEDO, J.A.G. Uso da glicerina bruta na alimentação animal. PUBVET, Londrina, V. 6, N. 26, Ed. 213, Art. 1421, 2012.

Já Parsons et al. (2008) avaliaram características da carcaça de novilhos em terminação, observaram ganho de peso médios diários de $12,6 \% ; 8,4 \%$ e $5,0 \%$ para bovinos alimentados com $2 \%, 4 \%$ e $8 \%$ de glicerina, respectivamente. Houve aumento da área do músculo longo longuíssimo quando $2 \%$ da dieta foi substituída pela glicerina.

Segundo Musselmam et al. (2008), ao avaliarem o desempenho de carcaças de cordeiros em confinamento numa concentração de 15, 30 e 45\% de glicerina bruta na dieta em substituição ao milho, os autores concluiram que numa dieta a $15 \%$ de glicerina não prejudica o desempenho dos animais em confinamento, nem altera a característica da carcaça quando comparado as concentrações de 30 e $45 \%$, onde foi observado menor rendimento de carcaça. Isso porque, $15 \%$ de glicerina atuou no organismo dos cordeiros fornecendo maior quantidade de energia quando comparada à alimentação a base de milho, já o excesso de gordura observado nas dietas acima de 30\% levou a menor ação das bactérias celulolíticas, compromentendo o desempenho animal. Avaliando a fermentação ruminal e desempenho de bezerros destinados a produção de carne, através da inclusão de 0, 5, 10 e 20\% de glicerina bruta substituindo grãos de milho, Ramos \& Kerley, 2012, observaram que quanto maior a inclusão da glicerina ocorre redução no consumo da matéria orgânica e melhoria da eficiência microbiana, não sendo observado nenhuma alteração na digestibilidade da fibra, nem alteração na produção de ácidos graxos voláteis, concluindo que a substituição até $20 \%$ do milho pela glicerina não afetou o desempenho e características da carcaça dos animais.

Avaliando o comportamento ingestivo de novilhas alimentadas em pastagens juntamente com glicerina a 2,8\%, 6,1\% e 9,1\% na matéria seca da dieta, condicionada numa calha de plástico, os autores observaram que a inclusão da glicerina até $9,1 \%$ não houve alteração no período de pastejo e ruminação, desempenho e digestibilidade dos alimentos, porém apresentou efeito negativo no crescimento das novilhas. 
TIGRE, J.S. e AZEVEDO, J.A.G. Uso da glicerina bruta na alimentação animal. PUBVET, Londrina, V. 6, N. 26, Ed. 213, Art. 1421, 2012.

\section{Desvantagens do uso da glicerina em ruminantes}

A glicerina e todos os subprodutos da indústria de biodiesel na alimentação de ruminantes apresentam seu uso limitado devido, principalmente, à composição de contaminantes, já que apresentam efeitos deletérios e presença de metabólitos bioativos (Abdalla et al., 2008).

Lage et al. (2010) através da inclusão de 0, 3, 6, 9 e 12\% de glicerina bruta na alimentação de cordeiros em terminação, observaram que não houve efeito dos níveis de glicerina bruta sobre os teores de umidade, extrato etéreo e cinzas do músculo Longissimus dorsi. Chegando a conclusão de que, a inclusão de glicerina na dieta diminuiu linearmente o teor de proteína bruta da carne, apresentando um fator negativo porque as proteínas estão envolvidas na transformação do músculo em carne, sendo esta, a principal fonte de proteína de alta qualidade na dieta humana.

\section{Glicerol na alimentação de Ruminantes X Não Ruminantes}

A glicerina produzida como um subproduto na manufatura de biodiesel pode ser uma fonte de energia útil para uso em dietas de frangos, porém, há preocupações em relação aos níveis aceitáveis de metanol residual produzidos durante o processo industrial (Cerrate et al. 2006).

Groesbek et al. (2008), substituindo óleo de soja por glicerol, observaram-se que houve melhoria na conversão alimentar, na digestibilidade, levando a melhoria no desempenho de suínos em crescimento. Avaliando a qualidade da carcaça de suínos em terminação, alimentados com glicerina associada a grãos secos, Duttlinger, et al., 2012, observaram que até $20 \%$ da inclusão da glicerina não afetou o desempenho e a qualidade da carcaça dos suínos, porém, acima desse valor ocorre redução da gordura e insaturação da carcaça. Já, Berenchtein et al. (2010), avaliando suínos em crescimento e terminação com a inclusão de 0, 3, 6 e $9 \%$ de glicerina na dieta, perceberam que houve redução do ganho de peso durante o período de crescimento, porém, pode-se incluir que a glicerina na dieta foi utilizada como ingrediente energético, por isso a inclusão até $9 \%$ na dieta dos suínos não altera o desempenho e 
TIGRE, J.S. e AZEVEDO, J.A.G. Uso da glicerina bruta na alimentação animal. PUBVET, Londrina, V. 6, N. 26, Ed. 213, Art. 1421, 2012.

características da carcaça. Já Schieck et al. (2010), avaliando a inclusão de $8 \%$ de glicerina bruta na dieta de suínos em terminação, observaram que o desempenho no crescimento foi semelhante aos animais com uma dieta a base de milho.

Avaliando porcas em lactação sob condições de estresse calórico substituindo milho e farelo de soja numa concentração de 3, 6 e $9 \%$ de glicerina bruta, Schieck, et al. (2010), observaram que o uso da glicerina não reduziu a temperatura corporal nem aumentou o teor de proteína do leite, concluindo que, porcas com uma dieta até $9 \%$ de glicerina não foi observado aumento da produção de leite quando comparada a porcas que recebiam a dieta padrão a base de milho e farelo de soja.

Avaliando frangos de corte no desempenho e rendimentos de carcaça numa dieta com inclusão de 0, 2, 4, 6, 8 e 10\% de glicerina bruta mista (glicerina bruta proveniente da industria de biodiesel de origem vegetal mistura a glicerina de origem animal), Guerra et al. (2011), concluíram que a inclusão até $5 \%$ não influenciou no desempenho zootécnico, acima desse valor observase aumento do consumo e excreção de água comprometendo a criação devido ao aumento da umidade da cama.

Avaliando em laboratório o metabolismo de frangos de corte machos a partir do $24^{\circ}$ dia de vida, em que foi feita substituição do amido por glicerina por um período de oito dias, Raber et al. (2009) observaram que a inclusão da glicerina na dieta promoveu maior ganho de peso e melhor conversão alimentar, concluindo que essa melhoria foi devido ao aumento da densidade calórica, melhor disponibilidade de nutrientes na ração, aumento dos ácidos graxos voláteis proporcionando eficiência energética. Dozier et al. (2008) determinaram a EMAn (energia metabolizável aparente corrigida para retenção de nitrogênio) do glicerol a 0, 3, 6 e 9\% na dieta de frangos com diferentes idades, encontrando valores de $3621 \mathrm{kcal} / \mathrm{kg}$, para frangos de 4 a 11 dias de idade, $3331 \mathrm{kcal} / \mathrm{kg}$, para frangos com 17 a 24 dias de idade e $3349 \mathrm{kcal} / \mathrm{kg}$ para frangos com 38 a 45 dias de idade. Estes valores são semelhantes ao da quantidade de energia do glicerol, por isso, pode-se dizer 
TIGRE, J.S. e AZEVEDO, J.A.G. Uso da glicerina bruta na alimentação animal. PUBVET, Londrina, V. 6, N. 26, Ed. 213, Art. 1421, 2012.

que este ingrediente apresenta alta digestibilidade, além disso é utilizada de forma eficiente por frangos de corte.

Swiatkiewicz \& Koreleski 2009).

Swiatkiewicz \& Koreleski (2009), observando a qualidade dos ovos de galinhas poedeiras que receberam uma dieta a base de glicerina $(6 \%)$ em substituição ao milho, não apresentou nenhum efeito prejudicial no desempenho das poedeiras e na qualidade dos ovos.

Através da avaliação das análises do uso da glicerina na alimentação de não ruminantes principalmente suínos e aves, podemos concluir que a glicerina assim como visualizado nos ruminantes, depende de uma porcentagem adequada na dieta, para promover melhoria no desempenho desses animais, e sua ação no organismo é principalmente como fonte energética.

\section{CONCLUSÕES}

Os resíduos do biodiesel, principalmente a glicerina pode ser usada na alimentação animal como fonte de energia, além de diminuir o impacto ambiental causado por acúmulo de resíduos na natureza, já que os ruminantes se adaptam a nova dieta sem afetar seu rendimento e sem provocar alterações nos microrganismos do rúmen, estes resíduos são uma boa alternativa para as regiões onde existem de alimentos ao longo do ano, não diminuindo a produção animal.

Em regiões que existem fábricas de biodiesel a glicerina apresenta menor custo ao produtor quando comparado ao custo do milho. Porém, novos estudos in vivo devem ser realizados com o objetivo de determinar a melhor forma de utilização em relação à porcentagem na ração, composição química, riscos de intoxicação, existência de dose letal e espécies que melhor se adaptam ao seu uso, bem como sua interação com outros ingredientes da ração. 


\section{REFERENCIAS BIBLIOGRÁFICAS}

ABDALLA, A.L.; SILVA FILHO, J.C.; GODOIS, A.R. et al. Utilização de subprodutos da indústria de biodiesel na alimentação de ruminantes. Revista Brasileira de Zootecnia, Viçosa, v.37, p. 260-268, 2008.

ANP - Agência Nacional do Petróleo, Gás Natural e Biocombustíveis. Disponível em: <http://www.anp.gov.br/?pg=60127chebust=13315> acesso em: 15 de maio de 2012.

BERENCHTEIN, B.; COSTA, L.B.; BRÁZ, D.B. et al. Utilização de glicerol na dieta de suínos em crescimento e terminação. Revista Brasileira de Zootecnia. v. 39, n. 7, p. 1491-1496, 2010.

CERRATE, S.; YAN, F., WANG, Z.; COTO, C.; SACAKLI, P.; WALDROUP, P.W. Evaluation of Glycerine from Biodiesel Production as a Feed Ingredient for Broilers. International Journal of Poultry Science, v. 5, n. 11,p. 1001-1007, 2006.

CHUNG, I.H.; RICO, D.E.; MARTINEZ, C.M. et al. Effects of Feeding Dry Glycerin to Early Postpartum Holstein DairyCows on Lactational Performance and Metabolic Profiles. Journal Dairy Science. v. 90, p. 5682-5691, 2007.

DEFRAIN, J.M.; HIPPEN, A.R.; KALSCHEUR, K.F. et al. Feeding glycerol to transition dairy cows: effects on blood metabolites and lactation performance. Journal Dairy Science. v. 87, p. 4195-4206, 2004.

DOZIER, W.A.; KERR, B. J.; CORZO, A. et al. 2008. Apparent Metabolizable Energy of Glycerin for Broiler Chickens. Poultry Science. v. 87, n. 2, p. 317-322, 2008.

DUTTLINGER, A.J.; DEROUCHEY, J.M.; TOKACH, M.D. et al. Effects of increasing crude glyceroland dried distillers grains with solubles on growth performance, carcass characteristics, and carcass fat quality of finishing pigs. Jounal of Animal Science. v. 90, $n$. 3, p. 840-852, 2012.

DONKIN, S.S.; DOANE, P.H. Glycerol from Biodiesel Production: The New Corn for Dairy Cattle. Revista Brasileira de Zootecnia, Viçosa, 2008. Disponível em: <http://www.scielo.br/scielo.php?pid=S1516359t=sci_arttext>Acesso em 14 de abril de 2012.

DONKIN, S.S.; KOSER, S.L.; WHITE, H.M.; et al. Feeding value of glycerol as a replacement for corn grain in rations fed to lactating dairy cows. Journal of Dairy Science, v. 92, p. 51115119, 2009.

DRACKLEY, J.K. Glycerin as a Potential Feed Ingredient for Dairy Cattle. Illiny Dairy Net, Illinois, 2007. Disponível em: <http://www.livestocktrail.uiuc.u>. Acesso 14 de abril de 2012.

FARIAS, M.F.; SILVA, R.R.; ZAWADZKI. F. et al. Glycerin levels for crossbred heifers supplemented in pasture: intake behavior. Acta Scientiarum. Animal Science. v, 34, n. 1, p. 63-69, 2012.

FDA. 2006. Code of Federal Regulations, 21 CFR 582.1320, Title 21, Vol. 6, 21CFR582.1320. Disponível em <http://edocket.access.gpo.gov/cfr_2002>. Acesso: 10 de abril de 2012.

FERREIRA, M.A.; SILVA, F.M.; BISPO, S.V. et al. Estratégias na suplementação de vacas leiteiras no semi-árido do Brasil, Revista Brasileira de Zootecnia, Viçosa, v. 38, p.322-329, 2009. 
GUERRA, L.R.H.; MURAKAMI, A.E.; GRACIA, A.F.Q.M. et al. Glicerina bruta mista na alimentação de frangos de corte (1 a 42 dias). Revista Brasileira de Saúde e Produção Animal. v. 12, n. 4, p. 1038-1050, 2011.

GROESBECK, C.N.; MCKINNEY, L.J.; DEROUCHEY, J.M. et al. Effect of crude glycerol on pellet mill production and nursery pig growth performance. Journal of Animal Science. $v$ 85, p. 201-202, 2008.

LAGE, J.F.; PAULINO, P.V.R.; PEREIRA, L.G.R. et al. Glicerina bruta na dieta de cordeiros terminados em confinamento. Pesquisa Agropecuária Brasileira. v. 45, n. 9, p. 1012-1020, 2010.

$\mathrm{MACH}, \mathrm{N} . ; \mathrm{BACH}, \mathrm{A}$; DEVANT, M. Effects of crude glycerin supplementation on performance and meat quality of Holstein bulls fed high-concentrate diets. Journal of Animal Science, v. 87, p. 632-638, 2009.

MUSSELMAN, A.F.; EMON, M.L.; GUNN, P.J.; et al. Effects of Crude Glycerin on Feedlot Performance and Carcass Characteristics of Market Lambs. American Society of Animal Sciences, v. 59, p. 353-355, 2008.

NIELSEN, N.I.; INGVARTSEN K.L. Propylene glycol for dairy cows: A review of the metabolism of propylene glycol and its effects on physiological parameters, feed intake, milk production and risk of ketosis. Animal Feed Science Technology, v. 115, p. 191-213, 2004.

OSBORNE, V. R.; ODONGO, N.E.; CANT, J.P. et al. Effects of supplementing glycerol and soybean oil in drinking water on feed and water intake, energy balance, and production performance of periparturient dairy cows. Journal of Dairy Science, v. 92, p. 698-707, 2009.

PARSONS, G.L.; SHELOR, M.K.; DROUILLARD, J.S. Performance and carcass traits of finishing heifers fed crude glycerin. Journal of Animal Science, Manhattan, 2008. Disponível em: <http://jas.fass.org/cgi/content87/2/653>. Acesso em: 14 de abril de 2012.

PERES, J.R.R.; FREITAS JUNIOR, E.; GAZZONI, D.L. Biocombustiveis. Uma oportunidade para o agronegócio brasileiro. Revista de Política Agrícola, Brasília, v. 1, p. 31-41, 2005.

QUINTELA, C.M.; TEIXEIRA, L.S.G.; KORNE, M.G.A. et al. Cadeia do biodiesel da banCada à indústria: uma visão geral Com prospe Cção de tarefas e oportunidades para p\&d\&. Química Nova. v. 32, n. 3, p. 793-808, 2009.

RAMOS, M.H.; KERLEY, M.S. Effect of dietary crude glycerol level on ruminal fermentation in continuous culture and growth performance of beef calves. Jounal of Animal Science. v. 90, n. 3, p. 892-899, 2012.

RABER, M.R.; RIBEIRO, A.M.L.; KESSLER, A.M.; ARNAIZ, V. Suplementação de glicerol ou lecitina em diferentes níveis de ácidos graxos livres em dietas para frangos de corte. Ciência Animal Brasileira, v. 10, n3, p. 745-753, 2009.

ROGER, V.; FONTY, G.; ANDRÉ, C.; GOUET, P. Effects of Glycerol on the Growth, Adhesion, and Cellulolytic Activity of Rumen Cellulolytic Bacteria and Anaerobic Fungi. Current Microbiology, New York, v. 25, p. 197-201, 2008.

SCHIECK, S.J.; SHURSON, K.B.J.; JOHNSTON, L.J. Evaluation of glycerol, a biodiesel coproduct, in grow-finish pig diets to support growth and pork quality. Journal of Animal Science. v. 88, p. 3927-3925, 2010.

SCHIECK, S.J.; KERR, S.K.; BAIDOO, G.C. et. al. Use of crude glycerol, a biodiesel coproduct, in diets for lactating sows. Journal of Animal Science. v. 88, p. 2648-2656, 2010. 
SWIATKIEWICZ, S; KORELESKI, J. Effect of crude glycerin level in the diet of laying hens on egg performance and nutrient utilization. Poultry Science. v, 88, n. 3, p. 615-619, 2009. 